\title{
Prognostic Importance of Exercise Brain Natriuretic Peptide in Asymptomatic Chronic Organic Severe Mitral Regurgitation: An Observational Study
}

\author{
Santosh Kumar Sinha ${ }^{\mathrm{a}, \mathrm{b}}$, Shalini Garga ${ }^{\mathrm{a}}$, Ramesh Thakur ${ }^{\mathrm{a}}$, Vinay Krishna ${ }^{\mathrm{a}}$, Karandeep Singh ${ }^{\mathrm{a}}$, \\ Mohit Sachan $^{\mathrm{a}}$, Amit Goel ${ }^{\mathrm{a}}$, Mahamdula Razi ${ }^{\mathrm{a}}$, Umeshwar Pandey ${ }^{\mathrm{a}}$, Chandra Mohan Varma ${ }^{\mathrm{a}}$
}

\begin{abstract}
Background: The optimal timing of surgery in patients with chronic organic severe mitral regurgitation (MR) continues to be debated, especially for those who are asymptomatic. The aim of the study was to determine independent and additive prognostic value of exercise brain natriuretic peptide (eBNP) in patients with severe asymptomatic MR and normal left ventricular ejection fraction (LVEF).
\end{abstract}

Methods: Two hundred twenty-three consecutive patients with severe MR defined by effective regurgitant orifice (ERO) area $\geq 40$ $\mathrm{mm}^{2}$ and/or residual volume $\geq 60 \mathrm{~mL}, \mathrm{LVEF}>60 \%$, and normal LV end-systolic diameter $<40 \mathrm{~mm}$ underwent symptom limited exercise treadmill test (TMT). Echocardiography was done immediately after exercise. Data were obtained within 3 minutes of peak exercise. BNP levels were assessed before echo (after 30 minutes of supine rest) and at exercise (i.e., within the 3 minutes of the end of effort). Patients were followed up every 3 months up to 15 months for major adverse cardiac events (MACEs) (cardiovascular death, need for mitral valve surgery and hospitalization for acute pulmonary edema or heart failure).

Results: Mean age was $31.2 \pm 9$ years (range: 18 - 40) with majority being male $(n=153 ; 68 \%)$. Etiologies were rheumatic $(n=201$; $90 \%)$, mitral valve prolapse $(\mathrm{n}=17 ; 7.6 \%)$ and hypertrophic cardiomyopathy $(\mathrm{n}=5 ; 2.4 \%)$. BNP level significantly increased from rest $(65.24 \pm 43.92 \mathrm{pg} / \mathrm{mL}$; median: $43.5 \mathrm{pg} / \mathrm{mL})$ to exercise $(100.24 \pm$ $98.24 \mathrm{pg} / \mathrm{mL}$; median: $66.5 \mathrm{pg} / \mathrm{mL}$; $\mathrm{P}<0.001)$. Patients were divided into three tertiles according to eBNP levels $\left(\mathrm{T}_{1}=15-44 ; \mathrm{T}_{2}=45-\right.$ $\left.104 ; \mathrm{T}_{3}=105-400\right)$. There was trend for significantly lower exercise time in $\mathrm{T}_{3}$. During TMT, 66 (29.5\%) stopped exercise due to dyspnea. They had similar resting BNP level compared with others but had significantly higher eBNP level $(136 \pm 109.7 \mathrm{pg} / \mathrm{mL}$ vs. $84.88 \pm 90.2 \mathrm{pg} /$ $\mathrm{mL} ; \mathrm{P}<0.001)$. During follow-up (15 months), MACE occurred in

Manuscript accepted for publication August 16, 2016

aDepartment of Cardiology, LPS Institute of Cardiology, G. S. V. M. Medical College, Kanpur, Uttar Pradesh 208002, India

${ }^{b}$ Corresponding Author: Santosh Kumar Sinha, Department of Cardiology, LPS Institute of Cardiology, G. S. V. M. Medical College, Kanpur, Uttar Pradesh 208002, India. Email: fionasan@rediffmail.com

doi: http://dx.doi.org/10.14740/jocmr2680w
83 patients (37.2\%): mitral valve replacement (MVR) in 59 patients (symptomatic: 43; LV dilatation or dysfunction: 9; both symptoms and dilatation/dysfunction: 7), 17 hospitalizations for congestive heart failure, five patients developing acute pulmonary edema and atrial fibrillation in remaining two patients. This was $7.6 \%, 35 \%$ and $69 \%$ in $\mathrm{T}_{1}, \mathrm{~T}_{2}$ and $\mathrm{T}_{3}$, respectively and had significantly higher eBNP level than without any event $(165 \pm 119 \mathrm{pg} / \mathrm{mL}$ vs. $57 \pm 48 \mathrm{pg} / \mathrm{mL}$; P $<0.001)$. Using receiver operating characteristic curve analysis, the best cut-off value of eBNP level to predict cardiac events was $90 \mathrm{pg} /$ $\mathrm{mL}$ (sensitivity: $75 \%$; specificity: $88.6 \%$; positive predictive value: $79 \%$; negative predictive value: $83.9 \%$ ).

Conclusion: In asymptomatic patients, eBNP level provides incremental prognostic value beyond echocardiographic data and those with elevated eBNP should be considered at high risk for reduced event-free survival and might be considered for early MVR.

Keywords: Effective regurgitant orifice area; Mitral regurgitation; Exercise brain natriuretic peptide; MACE; Tertiles; Dilatation; Dysfunction; Receiver operating characteristic curve; Mitral valve replacement

\section{Introduction}

The mitral valve apparatus is a complex structure consisting of the mitral leaflets, chordae tendineae, papillary muscles, and mitral annulus. Abnormalities of any of these structures may cause mitral regurgitation (MR) [1]. Causes could be inflammatory such as rheumatic heart disease and connective tissue disorders; degenerative such as myxomatous degeneration of mitral valve leaflets or annulus; infective such as infective endocarditis; structural such as ruptured chordae tendineae, papillary muscle dysfunction (ischemia or myocardial infarction) and annular dilation; and congenital such as mitral valve clefts or fenestrations, parachute mitral valve, to name a few.

Because the regurgitant mitral orifice is functionally in parallel with the aortic valve, the impedance to ventricular emptying is reduced in patients with MR. Consequently, MR enhances left ventricular (LV) emptying. Almost $50 \%$ of the regurgitant volume (RV) is ejected into the left atrium (LA) before the aortic valve opens. The RV depends on a combination of the instantaneous size of the regurgitant orifice and 
the (reverse) pressure gradient between the LV and LA [2]. In chronic MR, left ventricular end-diastolic volume (LVEDV) increases and left ventricular end-systolic volume (LVESV) returns to normal. By means of the Laplace principle, the increased LVEDV increases wall tension to normal or supernormal levels in the so-called chronic compensated stage [3]. The resultant increase in LVEDV and mitral annular diameter may create a vicious circle, in which MR begets to more MR. In patients with chronic MR, eccentric hypertrophy develops but reduces after load permits maintenance of ejection fraction $(\mathrm{EF})$ in the normal to supernormal range. In most patients with severe MR, compensation is maintained for years, but in some prolonged hemodynamic overload ultimately leads to myocardial decompensation [4]. LVESV, preload and after load all increase, whereas EF and stroke volume decline.

Patients develop symptoms because of elevated LA and pulmonary venous pressures related to the RV despite no apparent change in ejection phase indices such as EF, fractional fiber shortening, and velocity of circumferential fiber shortening (VCF) as these are after load dependent which is reduced initially [4]. However, in other patients, major symptoms reflect serious contractile dysfunction, at which time these indices have declined to low-normal or below-normal levels. Therefore, values in the low-normal range for the ejection phase indices in patients with chronic MR may actually reflect impaired myocardial function, whereas moderately reduced values (EF: 40-50\%) signify severe, often irreversible, impairment of contractility, identifying patients who may do poorly after surgical correction of the MR. Subjects with EF $<60 \%$ and/or end-systolic diameter (ESD) $\geq 40 \mathrm{~mm}$ should be considered as patients with manifest LV dysfunction even if they are asymptomatic and, where it is not contraindicated, they should receive salvage surgery [5]. This implies a discrepancy with current recommendations, but using $\mathrm{EF}<60 \%$ and ESD $\geq 40 \mathrm{~mm}$ as indicators for surgery may involve too long a delay and will lead to poorer medium- and long-term survival.

The optimal timing of surgery in patients with asymptomatic severe MR continues to be debated. Current guidelines recommend for intervention in presence of symptoms, pulmonary hypertension $(\mathrm{PAH})$, new onset atrial fibrillation (AF) or incipient LV dysfunction. LVESD, LA size and EF have been found to allow risk stratification in asymptomatic patients among several echocardiographic parameters. Effective regurgitant orifice (ERO) area, a marker of hemodynamic consequences, has also been shown to correlate with adverse outcomes. Echocardiography, however, is operator dependent and has several limitations. Therefore, there is a growing need for other objective measures to help identify patients with severe MR with subtle LV dysfunction.

\section{Risk stratification of asymptomatic patients}

Because the outcomes of MV surgery are not optimal in all cases, all authoritative guidelines include clinically accessible measures of LV remodeling and "function" to identify asymptomatic patients at higher risk and should help ascertain the ideal timing of intervention to preserve LV function and not simply avert a poor outcome. Symptoms are often unreliable as they are subjective but provide reassurance that intervention can be safely delayed in asymptomatic patients. It can be also done by rest and stress echocardiography, tissue Doppler and myocardial deformation imaging and natriuretic peptides.

Apart from LV dimensions, volumes and function, direct quantization of MR is performed by the proximal isovelocity surface area (PISA) technique. While exponents of the PISA method vouch for its accuracy and reproducibility [6], it has only modest reliability and significant interobserver variability. Other limitations of PISA technique include geometric assumptions of the flow convergence zone [7]. Given these pitfalls, assessment of MR severity should integrate quantitative and qualitative data, including vena contracta width, and pulmonary vein systolic flow reversal. Stress echocardiography can evaluate contractile reserve (CR) and also unmask PAH in asymptomatic patients. Exercise-induced PAH (pulmonary artery systolic pressure (PASP) $>60 \mathrm{~mm} \mathrm{Hg}$ ) is associated with markedly lower 2-year symptom-free survival, and appears superior to resting PAH for predicting the occurrence of symptoms [8].

In chronic organic MR, incipient LV dysfunction may also be detected by tissue Doppler imaging (TDI) based on assessment of LV long axis function which appears to be deranged earlier than radial shortening. Haluska et al [9] showed that peak annular systolic velocity $\left(\mathrm{S}_{\mathrm{m}}\right)$ was the only resting echocardiographic parameter that could discriminate patients with and without cardiac rehabilitation (CR). The differences in peak $\mathrm{S}_{\mathrm{m}}$ were even greater after stress. In one study, $\mathrm{S}_{\mathrm{m}} \leq 10$ $\mathrm{cm} / \mathrm{s}$ was independently associated with a $>10 \%$ postoperative reduction in LVEF [10].

Compared to TDI, myocardial strain imaging is less influenced by cardiac translation and tethering [11, 12]. "Pseudonormalization" of myocardial strain in chronic MR, whereby fiber shortening is enhanced in the compensated state but later decreases with disease progression, suggests that normalization for preload or LV geometry is required to appropriately interpret this parameter [13]. Therefore, reports are conflicting on the value of preoperative speckle-tracking strain imaging in predicting postoperative LV dysfunction $[14,15]$.

\section{Brain natriuretic peptide (BNP)}

Human cardiocytes manufacture a family of structurally related peptides whose release is stimulated by hemodynamic stress as wall stretch, ventricular dilatation and/or increased pressure resulting from fluid overload, ventricular hypertrophy, systemic hypertension, hypervolemia, PAH, increasing age, increased LA size and hyperthyroidism, to name a few (Table 1). It consists of five structurally similar peptides, i.e. atrial natriuretic peptide (ANP), urodilatin (an isoform of ANP), BNP, C-type natriuretic peptide (CNP) and dendroaspis natriuretic peptide (DNP) [16]. Of them, BNP and its related cleavage products have emerged as superior markers for congestive heart failure (CHF) and LV dysfunction because of its rapid upregulation at the transcriptional level, more stable than other peptides and more sensitive to ventricular dysfunction.

Natriuretic peptides have much potential in the risk stratification of asymptomatic patients with hemodynamically sig- 
Table 1. Natriuretic Peptides and Its Types

\begin{tabular}{lllll} 
Natriuretic peptide & Amino acid length & $\mathbf{T}_{\mathbf{1 / 2}}(\mathbf{m i n})$ & Source & Stimulus for release \\
\hline ANP & 28 & 3 & Atria & $\uparrow$ atrial pressure, stretching \\
NANP & 98 & 54 & Atria & $\uparrow$ atrial pressure, stretching \\
NT-ProBNP & 76 & $60-120$ & Ventricles & $\uparrow$ ventricular volume, stretching, end-diastolic pressure \\
BNP & 32 & 22 & Ventricles & $\uparrow$ ventricular volume, stretching, end-diastolic pressure \\
CNP (two isoforms) & 53,22 & 42406 & Peripheral vessel & Unclear \\
\hline
\end{tabular}

ANP: atrial natriuretic peptide; NANP: N-terminal atrial natriuretic peptide; NT-ProBNP: N-terminal proB-type natriuretic peptide; BNP: B-type natriuretic peptide; CNP: C-type natriuretic peptide; $T_{1 / 2}$ : half life.

nificant valvular lesions well as in their routine surveillance and monitoring. In patients with primary MR, it is known to be a good surrogate marker of its consequences on the LV, LA and PASP [17-19] and is a powerful predictor of outcome. In the management of asymptomatic patients with MR, current ACC/ AHA and ESC guidelines for valvular heart disease recommend performing exercise testing in order to obtain objective assessment of symptomatic status and to assess the exercise tolerance. In addition, MR severity [20] and PASP [21] quantified at peak exercise are superior to these parameters evaluated at rest for predicting the occurrence of symptoms. Therefore, the measurement of BNP at exercise could provide an incremental value as compared with standard resting BNP for the risk stratification of patients with asymptomatic MR.

\section{Materials and Methods}

\section{Patients}

The aim of this study was to determine the independent and additive prognostic value of exercise brain natriuretic peptide (eBNP) over resting brain natriuretic peptide in patients with chronic organic severe asymptomatic MR and normal LV function. It was a prospective, single-center trial conducted in the Department of Cardiology, LPS Institute of Cardiology, G.S.V.M. Medical College, Kanpur, UP, India between October 2013 and March 2015. Three hundred twenty-five consecutive patients were enrolled with chronic severe organic asymptomatic MR as defined by ERO area $\geq 40 \mathrm{~mm}^{2}$, and/or $\mathrm{RV} \geq 60 \mathrm{~mL}$, preserved LVEF $>60 \%$ and LVESD $<40 \mathrm{~mm}$. Exclusion criteria were patients with LVESD $>40 \mathrm{~mm}$, LVEF $<60 \%$, permanent AF, with associated valve disease (aortic valve disease, moderate or severe mitral stenosis, or significant right organic valve disease), renal dysfunction ( $\mathrm{SCr}>2.5 \mathrm{mg}$ / $\mathrm{dL}$ ), ischemic MR, previous valve surgery, dilated cardiomyopathy (DCM), inadequate transthoracic echocardiogram (TTE) imaging window, and terminal disease with expected survival $\leq 1$ year. Informed consent was obtained from each patient enrolled in the study. Patients were followed up every 3 months up to 15 months. Endpoint cardiac events were defined as the occurrence of cardiovascular (CV) death, need for mitral valve surgery based on current guideline recommendation by ESC/ ACC/AHA, and hospitalization for acute pulmonary edema or $\mathrm{CHF}$.

\section{Data collection}

Enrolled patients underwent complete evaluation including detailed clinical examination and investigations including ECG and then were subjected to cardiac echocardiography and symptom limited exercise treadmill test (TMT). Coronary angiography was performed using the Judkins' method by radial route using Tiger catheter (Terumo Inc., Japan) as a part of their diagnostic protocol to rule out ischemic MR or DCM. Venous blood samples were withdrawn for quantification of BNP before echo (i.e., after $30 \mathrm{~min}$ of supine rest), and at exercise (i.e., within the $3 \mathrm{~min}$ of the end of effort) for eBNP using Alere triage BNP kits by Alere Triage MeterPro 55070 machine.

Dyspnea was graded according to the NYHA classification. All subjects underwent a symptom limited exercise TMT by standard Bruce protocol. Blood pressure was recorded at the end of each stage. Exercise was stopped in lieu of marked dyspnea, fatigue, chest discomfort, $\geq 2 \mathrm{~mm} \mathrm{ST}$ depression, and significant arrhythmia or slowing of heart rate and on patient request.

\section{Echo and exercise test protocol}

Echocardiography was performed with Vivid7 (GE) instrument. LVEDD and LVESD by M-mode in standard parasternal long-axis (PLAX) view using the leading edge methodology at end-diastole and end-systole, LVEDV/LVESV/LVEF by modified biplane Simpson's method, LA volume by arealength method, mitral E- and A-wave velocities by pulsedwave Doppler, Ea-wave velocity by tissue Doppler imaging in the septal position of the mitral annulus, MR quantification by quantitative Doppler with mitral and aortic stroke volumes, and PISA which was further averaged allowing calculation of $\mathrm{RV}$, regurgitation fraction (RF), and ERO area, PASP by regurgitant jet of tricuspid regurgitation (TR), comprehensive LV myocardial function by the global longitudinal strain (GLS) using 2D speckle tracking were analyzed. Furthermore, exercise echocardiographic images were obtained in the apical four-chamber view for LV volumes followed by TR jet velocity for PASP within 1 min of peak exercise.

\section{Statistical analysis}

Continuous variables were expressed as mean $\pm \mathrm{SD}$, while 
Table 2. Baseline Characteristics of Patients $(N=223)$

\begin{tabular}{ll}
\hline Variables & No. $(\%)$ \\
\hline Age (years) & $31.2 \pm 9$ \\
Sex (M:F) & $153 / 73(68 / 32)$ \\
Etiology & \\
$\quad$ Rheumatic & $201(90)$ \\
$\quad$ MVP & $17(7.6)$ \\
$\quad$ HCM & $5(2.4)$ \\
BNP $(\mathrm{pg} / \mathrm{mL})$ at rest & $65.24 \pm 43.92$ (median: 43.5$)$ \\
BNP $(\mathrm{pg} / \mathrm{mL})$ at exercise (eBNP) & $100.24 \pm 98.24$ (median: 66.5$)$ \\
$\quad \mathrm{T}_{1}(15-44)$ & $76(34 \%)$ \\
$\mathrm{T}_{2}(45-104)$ & $77(34 \%)$ \\
$\mathrm{T}_{3}(105-400)$ & $70(31 \%)$ \\
\hline
\end{tabular}

BNP: brain natriuretic peptide; MVP: mitral valve prolapse; HCM: hypertrophic cardiomyopathy.

discrete variables were presented as frequency and percentage. Patients were stratified in three tertiles according to eBNP level (post hoc analysis). Differences between groups were analyzed for statistical significance with one-way analysis of variance (ANOVA), $\chi^{2}$ test, or Fisher's exact test as appropriate. The statistical difference between resting and eBNP was obtained using paired $t$-test. Correlations between echocardiographic data and BNP level were assessed with linear regressions method. Sensitivity and specificity for prediction of the occurrence of events were determined for various cut-off values of eBNP level using receiver operating characteristic (ROC) curves. The impact of BNP level on outcome was assessed according to tertiles. Values of $\mathrm{P}<0.05$ were considered statistically significant. All statistical analyses were performed with STATISTICA version 7 (StatSoft Inc., Tulsa, OK, USA).

\section{Results}

\section{Baseline characteristics}

Baseline characteristics of patients are described in Table 2. Mean age was $31.2 \pm 9$ years (range: 18 - 40) with majority being male $(\mathrm{n}=153 ; 68 \%)$. The etiologies of chronic MR were rheumatic $(n=201 ; 90 \%)$, mitral valve prolapse $(n=17 ; 7.6 \%)$ and hypertrophic cardiomyopathy $(\mathrm{n}=5 ; 2.4 \%)$. BNP level at rest was $65.24 \pm 43.92 \mathrm{pg} / \mathrm{mL}$ (median: 43.5 ) with statistically significant rise to exercise level $(100.24 \pm 98.24 \mathrm{pg} / \mathrm{mL}$; median: 66.5; $\mathrm{P}<0.001)$. Patients were then divided into three tertiles based on eBNP level $\left(\mathrm{T}_{1}=15-44 \mathrm{pg} / \mathrm{mL} ; \mathrm{T}_{2}=45-\right.$ $\left.104 \mathrm{pg} / \mathrm{mL} ; \mathrm{T}_{3}=105-400 \mathrm{pg} / \mathrm{mL}\right)$. There were 76 (34\%), 77 $(34 \%)$ and $70(31 \%)$ in $\mathrm{T}_{1}, \mathrm{~T}_{2}$ and $\mathrm{T}_{3}$, respectively.

\section{Clinical and resting echocardiographic data according to tertile of peak eBNP distribution}

The average exercise time was $9.78 \pm 3.02$ min with no signifi- cant difference in peak systolic blood pressure (SBP), increase in SBP, peak heart rate except for a significantly lower exercise time in $T_{3}$. During exercise, 66 (29.5\%) stopped exercise due to dyspnea. Of note, patients who had dyspnea had similar resting BNP level $(66.13 \pm 43.84 \mathrm{pg} / \mathrm{mL}$ vs. $64.85 \pm 44.58$ $\mathrm{pg} / \mathrm{mL} ; \mathrm{P}=0.23)$ but significantly higher eBNP level (136 \pm $109.7 \mathrm{pg} / \mathrm{mL}$ vs. $84.88 \pm 90.2 \mathrm{pg} / \mathrm{mL} ; \mathrm{P}<0.001)$ compared with those who did not develop dyspnea. There were no significant differences in indexed LVESV $\left(21.5 \pm 2.4 \mathrm{~mL} / \mathrm{m}^{2}, 21.53\right.$ $\pm 2.6 \mathrm{~mL} / \mathrm{m}^{2}, 22.69 \pm 2.18 \mathrm{~mL} / \mathrm{m}^{2} ; \mathrm{P}=12$ ), indexed LVEDV $\left(68.7 \pm 6.15 \mathrm{~mL} / \mathrm{m}^{2}, 67.06 \pm 4.77 \mathrm{~mL} / \mathrm{m}^{2}, 67.44 \pm 5 \mathrm{~mL} / \mathrm{m}^{2} ; \mathrm{P}\right.$ $=0.5)$, LVEF $(68.17 \pm 3.14 \%, 66.7 \pm 2.86 \%, 67.56 \pm 3.16 \% ; \mathrm{P}=$ $0.6)$ except LVGLS $(-23 \pm 3 \%,-20 \pm 4 \%,-17 \pm 4 \%$; $\mathrm{P}<0.01)$ and E/Ea ratio $(11.65 \pm 1.32,13.8 \pm 1.01,15.05 \pm 2.03 ; \mathrm{P}=0.001)$ among $\mathrm{T}_{1}, \mathrm{~T}_{2}$ and $\mathrm{T}_{3}$, respectively. For MR severity, there were no differences in $\mathrm{RV}(70.6 \pm 4.17 \mathrm{~mL}, 87.53 \pm 11.67 \mathrm{~mL}, 81.68$ $\pm 10.27 \mathrm{~mL} ; \mathrm{P}=0.5)$ except ERO $\left(50.47 \pm 6.2 \mathrm{~mm}^{2}, 59.94 \pm\right.$ $\left.10.32 \mathrm{~mm}^{2}, 50.06 \pm 9.24 \mathrm{~mm}^{2} ; \mathrm{P}=0.08\right)$, indexed LA volume $\left(36 \pm 14 \mathrm{~mL} / \mathrm{m}^{2}, 39 \pm 14 \mathrm{~mL} / \mathrm{m}^{2}, 54 \pm 20 \mathrm{~mL} / \mathrm{m}^{2} ; \mathrm{P}<0.001\right)$ and PASP $(33.41 \pm 4.32 \mathrm{~mm} \mathrm{Hg}, 39.17 \pm 4.38 \mathrm{~mm} \mathrm{Hg}, 44$ $\pm 6.39 \mathrm{~mm} \mathrm{Hg} ; \mathrm{P}<0.02$ ) among $\mathrm{T}_{1}, \mathrm{~T}_{2}$ and $\mathrm{T}_{3}$, respectively (Table 3).

\section{Exercise echocardiographic data according to the tertiles of peak eBNP distribution}

There were no significant differences in indexed LVEDV (58 $\left.\pm 24 \mathrm{~mL} / \mathrm{m}^{2}, 59 \pm 19 \mathrm{~mL} / \mathrm{m}^{2}, 66 \pm 22 \mathrm{~mL} / \mathrm{m}^{2} ; \mathrm{P}=0.52\right)$, LVEF $(71 \pm 9 \%, 69 \pm 10 \%, 65 \pm 13 \% ; \mathrm{P}=0.13)$ except indexed LVESV $\left(18 \pm 7 \mathrm{~mL} / \mathrm{m}^{2}, 18 \pm 8 \mathrm{~mL} / \mathrm{m}^{2}, 26 \pm 11 \mathrm{~mL} / \mathrm{m}^{2} ; \mathrm{P}=0.06\right)$, LVGLS $(-27 \pm 5 \%,-23 \pm 5 \%,-17 \pm 5 \% ; \mathrm{P}<0.01)$ and E/Ea ratio $(13.52 \pm 1.42,15.17 \pm 0.81,18.87 \pm 2.30 ; \mathrm{P}=0.001)$ among $\mathrm{T}_{1}, \mathrm{~T}_{2}$ and $\mathrm{T}_{3}$, respectively. For MR severity, there were significant differences in RV $(72 \pm 5.9 \mathrm{~mL}, 82 \pm 40 \mathrm{~mL}, 86 \pm 34$ $\mathrm{mL} ; \mathrm{P}=0.09)$, ERO $\left(50.7 \pm 10 \mathrm{~mm}^{2}, 55.1 \pm 10.3 \mathrm{~mm}^{2}, 61 \pm\right.$ $\left.12.38 \mathrm{~mm}^{2} ; \mathrm{P}=0.04\right)$, indexed LA volume $\left(42 \pm 16 \mathrm{~mL} / \mathrm{m}^{2}\right.$, $\left.47 \pm 18 \mathrm{~mL} / \mathrm{m}^{2}, 52 \pm 16 \mathrm{~mL} / \mathrm{m}^{2} ; \mathrm{P}<0.001\right)$ and PASP $(59.06 \pm$ $8.4 \mathrm{~mm} \mathrm{Hg}, 64.11 \pm 7.4 \mathrm{~mm} \mathrm{Hg}, 74.7 \pm 7.8 \mathrm{~mm} \mathrm{Hg} ; \mathrm{P}<0.01)$ among $\mathrm{T}_{1}, \mathrm{~T}_{2}$ and $\mathrm{T}_{3}$, respectively (Table 4 ).

During follow-up (15 months), pre-defined cardiac events occurred in 83 patients (37.2\%): mitral valve replacement (MVR) in 59 (71\%) patients (symptomatic: 43 (51\%); LV dilatation or dysfunction: 9 (10\%); both symptoms and dilatation/ dysfunction: $7(8.4 \%)$ ). Twenty-four patients (29\%) experienced an event other than surgery (CHF hospitalizations: 17 (20\%), syncope: $2(2.5 \%)$ related to fast AF, and acute pulmonary edema: $5(6 \%)$ ). This was $7.6 \%, 35 \%$ and $69 \%$ in $\mathrm{T}_{1}, \mathrm{~T}_{2}$ and $\mathrm{T}_{3}$, respectively. These patients had a significantly higher eBNP level than without any event $(165 \pm 119 \mathrm{pg} / \mathrm{mL}$ vs. $57 \pm$ $48 \mathrm{pg} / \mathrm{mL} ; \mathrm{P}<0.001)$.

Using ROC curve analysis, the best cut-off value of eBNP level to predict cardiac events was $90 \mathrm{pg} / \mathrm{mL}$ (sensitivity: $75 \%$; specificity: $88.6 \%$; positive predictive value: $79 \%$; negative predictive value: $83.9 \%$ ). In addition, by restricting the analysis only to patients with a resting BNP level greater than median, i.e. $43.5 \mathrm{pg} / \mathrm{mL}, 36$ of 60 patients $(40 \%)$ whose BNP had increased from rest to exercise had a significantly lower 
Table 3. Clinical and Echocardiographic Data According to Tertile of Peak eBNP Distribution $(\mathrm{N}=223)$

\begin{tabular}{|c|c|c|c|c|}
\hline Variables & $\begin{array}{l}T_{1}(<15 \text { to } 44 \mathrm{pg} / \mathrm{mL}) \\
(\mathrm{n}=76)\end{array}$ & $\begin{array}{l}T_{2}(45-104 \mathrm{pg} / \mathrm{mL}) \\
(\mathrm{n}=77)\end{array}$ & $\begin{array}{l}T_{3}(105-400 \mathrm{pg} / \mathrm{mL}) \\
(n=70)\end{array}$ & $\mathbf{P}$ \\
\hline Age (years) & $29 \pm 11$ & $31 \pm 7$ & $32 \pm 8$ & 0.3 \\
\hline Height (m) & $1.53 \pm 0.5$ & $1.57 \pm 0.2$ & $1.56 \pm 0.1$ & 0.7 \\
\hline Weight (kg) & $65 \pm 12$ & $63 \pm 9.6$ & $60.7 \pm 14$ & 0.8 \\
\hline Peak SBP (mm Hg) & $159 \pm 10$ & $158 \pm 12$ & $150 \pm 18$ & 0.3 \\
\hline Increase in SBP (mm Hg) & $47 \pm 10$ & $37 \pm 8$ & $35 \pm 8$ & 0.6 \\
\hline Peak HR & $154 \pm 8$ & $151 \pm 7$ & $146 \pm 10$ & 0.2 \\
\hline Resting BNP (pg/mL) & $30.3 \pm 8.2$ & $44.35 \pm 17.2$ & $124.5 \pm 17.1$ & $<0.001$ \\
\hline Indexed LVEDV $\left(\mathrm{mL} / \mathrm{m}^{2}\right)$ & $68.7 \pm 6.15$ & $67.06 \pm 4.77$ & $67.44 \pm 5$ & 0.5 \\
\hline LVEF (\%) & $68.17 \pm 3.14$ & $66.7 \pm 2.86$ & $67.56 \pm 3.16$ & 0.6 \\
\hline LVGLS (\%) & $-23 \pm 3$ & $-20 \pm 4$ & $-17 \pm 4$ & $<0.01$ \\
\hline $\mathrm{E} / \mathrm{Ea}$ ratio & $11.65 \pm 1.32$ & $13.8 \pm 1.01$ & $15.05 \pm 2.03$ & 0.001 \\
\hline \multicolumn{5}{|l|}{ MR severity } \\
\hline $\operatorname{ERO}\left(\mathrm{mm}^{2}\right)$ & $50.47 \pm 6.2$ & $59.94 \pm 10.32$ & $50.06 \pm 9.24$ & 0.08 \\
\hline $\mathrm{RV}(\mathrm{mL})$ & $70.6 \pm 4.17$ & $87.53 \pm 11.67$ & $81.68 \pm 10.27$ & 0.5 \\
\hline Indexed LA volume $\left(\mathrm{mL} / \mathrm{m}^{2}\right)$ & $36 \pm 14$ & $39 \pm 14$ & $54 \pm 20$ & $<0.001$ \\
\hline PASP (mm Hg) & $33.41 \pm 4.32$ & $39.17 \pm 4.38$ & $44 \pm 6.39$ & $<0.02$ \\
\hline
\end{tabular}

SBP: systolic blood pressure; ERO: effective regurgitant orifice; HR: heart rate; LVESV: left ventricular end-systolic volume; LVEDV: left ventricular end-diastolic volume; LVEF: left ventricular ejection fraction; GLS: global longitudinal strain; PASP: pulmonary artery systolic pressure; RV: regurgitant volume.

Table 4. Exercise Echocardiographic Data According to Tertiles of Peak eBNP Distribution $(\mathrm{N}=223)$

\begin{tabular}{|c|c|c|c|c|}
\hline Variables & $\begin{array}{l}T_{1}(<15-44 \mathrm{pg} / \mathrm{mL}) \\
(\mathrm{n}=77)\end{array}$ & $\begin{array}{l}T_{2}(45-104 \mathrm{pg} / \mathrm{mL}) \\
(\mathrm{n}=76)\end{array}$ & $\begin{array}{l}T_{3}(105-400 \mathrm{pg} / \mathrm{mL}) \\
(\mathrm{n}=70)\end{array}$ & P value \\
\hline \multicolumn{5}{|l|}{ LV geometry and function at exercise } \\
\hline Indexed LVESV $\left(\mathrm{mL} / \mathrm{m}^{2}\right)$ & $18 \pm 7$ & $18 \pm 8$ & $26 \pm 11$ & 0.06 \\
\hline Indexed LVEDV (mL/m²) & $58 \pm 24$ & $59 \pm 19$ & $66 \pm 22$ & 0.52 \\
\hline LVEF (\%) & $71 \pm 9$ & $69 \pm 10$ & $65 \pm 13$ & 0.13 \\
\hline LVGLS (\%) & $-27 \pm 5$ & $-23 \pm 5$ & $-17 \pm 5$ & $<0.01$ \\
\hline E/Ea ratio & $13.52 \pm 1.42$ & $15.17 \pm 0.81$ & $18.87 \pm 2.30$ & 0.001 \\
\hline \multicolumn{5}{|l|}{ Exercise MR severity } \\
\hline $\operatorname{ERO}\left(\mathrm{mm}^{2}\right)$ & $50.7 \pm 10$ & $55.1 \pm 10.3$ & $61 \pm 12.38$ & 0.04 \\
\hline $\mathrm{RV}(\mathrm{mL})$ & $72 \pm 5.9$ & $82 \pm 40$ & $86 \pm 34$ & 0.09 \\
\hline Indexed LA volume $\left(\mathrm{mL} / \mathrm{m}^{2}\right)$ & $42 \pm 16$ & $47 \pm 18$ & $52 \pm 16$ & 0.03 \\
\hline PASP (mm Hg) & $59.06 \pm 8.4$ & $64.11 \pm 7.4$ & $74.7 \pm 7.8$ & $<0.01$ \\
\hline
\end{tabular}

ERO: effective regurgitant orifice; HR: heart rate; LVESV: left ventricular end-systolic volume; LVEDV: left ventricular end-diastolic volume; LVEF: left ventricular ejection fraction; GLS: global longitudinal strain; PASP: pulmonary artery systolic pressure; RV: regurgitant volume. 
event-free survival.

\section{Discussion}

In normal healthy subjects, BNP significantly increases following standard treadmill exercise which is unrelated to exerciseinduced hemoconcentration, gender, age, or body mass index [8]. Similar variations of BNP level after exercise have also reported in various cardiac diseases. In patients with chronic heart failure, exercise levels of BNP appear to be more reliable than their resting level as markers of LV systolic dysfunction and dimensions $[22,23]$ implying that a marked increase in BNP during exercise might occur early in the course of developing chronic heart failure. In addition, eBNP correlates with exercise capacity in such patients.

In our study, patients with asymptomatic MR with normal LV dimensions and function, elevated eBNP was independently associated with subclinical impairment of systolic and diastolic LV function, exercise MR severity, LA dilatation, and reduced cardiac event-free survival. Of note, exercise LV longitudinal function is the main determinant of eBNP, whereas neither resting or exercise LVEF nor the degree of MR at rest was significantly associated with eBNP. Also exercise LVGLS was significantly reduced in $T_{3}(-17 \pm 5)$ compared to $T_{2}$ and $T_{1}$ $(-27 \pm 5$ and $-23 \pm 5)$, implying EF lacks sensitivity to identify subtle or latent impairment in myocardial systolic function.

Reduced LVGLS has previously been shown to be superior to LVEF to predict persistence of LV systolic dysfunction and worse functional capacity after mitral valve surgery [24]. Consequently, LVGLS which is a rapid, simple, and reproducible echocardiographic parameter, may be integrated into the routine evaluation of patients with MR. Furthermore, the findings of this study reveal that eBNP could be used as a surrogate marker of LV longitudinal dysfunction during exercise regardless of the severity of MR.

eBNP level also correlated well with the estimate of elevated resting LV filling pressures and abnormal exercise LV filling response as significantly higher exercise $\mathrm{E} / \mathrm{Ea}$ ratio in $\mathrm{T}_{3}(18.87 \pm 2.30)$ compared to $\mathrm{T}_{1}$ and $\mathrm{T}_{2}(13.52 \pm 1.42$ and $15.17 \pm 0.81)$. Previous studies by Mak et al [25] also reported that the combined consideration of BNP and the E/Ea ratio is helpful in the assessment of LV diastolic function. The higher LA volume index obtained in $\mathrm{T}_{3}$ compared to $\mathrm{T}_{1}$ and $\mathrm{T}_{2}(42 \pm$ 16 and $47 \pm 18$ ) may be related to the concomitant impact of elevated LV filling pressures. Similar findings were concluded from studies by Le Tourneau et al [26] and Rusinaru et al [27] that LA enlargement is a good marker of advanced stage of primary MR. In light of these results, exercise BNP appears to be a valuable surrogate marker of LV diastolic and systolic dysfunctions and of their potential worsening during exercise.

The management of asymptomatic patients with preserved LV function remains controversial as revealed in "watchful waiting" strategy proposed by Rosenhek et al [28] and "early surgery" proposed by Montant et al [29]. It underlines the importance to refine the identification of high-risk patients as those with low risk could be safely managed conservatively with regular follow-up, whereas those identified at higher risk could be referred for early surgery. Nevertheless, such management necessitates the identification of trustworthy markers able to discriminate patients at low vs. high risk of developing symptoms under conservative management. Parameters and criteria recommended in the guidelines (LV dilatation/ dysfunction, $\mathrm{AF}$, and $\mathrm{PAH}$ ) are generally associated with reduced postoperative survival. The measurement of resting BNP may aid the clinical decision making for asymptomatic MR patients as shown by Sutton et al [30], Detaint et al [17], and Pizarro et al [31]. Magne et al [21] showed that eBNP may improve risk stratification beyond obtained from demographics, echocardiographic data, and resting BNP, and may thus be helpful to unmask patients at high risk of developing rapid cardiac events. In their study of 113 asymptomatic patients with moderate to severe degenerative MR and preserved LV function, comprehensive resting and exercise echocardiography was performed where BNP level significantly increased from rest to exercise $(\mathrm{P}<0.0001)$. The independent determinants of eBNP were resting E/Ea ratio $(\mathrm{P}=0.043)$, indexed LA volume $(\mathrm{P}=0.022)$, and exercise LVGLS $(\mathrm{P}=0.001)$ with a significant graded relationship between increasing BNP level at exercise and increased incidence of cardiac events (death, CHF, need for MVR driven by symptoms, or LV dilatation/dysfunction onset) at 1 year $(11+5 \%$ vs. $14+6 \%$ vs. $43.5+9 \%)$ and 2 years $(21+7 \%$ vs. $40+8 \%$ vs. $67+9 \%$ ) in three tertiles. On multivariable analysis, after adjustment for demographic, echocardiographic data and resting BNP level, eBNP remained significantly associated with increased risk of cardiac events during the follow-up (hazard ratio 2.8 and 3.4 for $\mathrm{T}_{2}$ and $\mathrm{T}_{3}$ as compared with $\mathrm{T}_{1}$ ). The best cut-off value of eBNP level to predict cardiac events was $64 \mathrm{pg} / \mathrm{mL}$ (sensitivity: $87 \%$; specificity: $61 \%$ ). The present study also showed comparable results with best cut-off value of eBNP $90 \mathrm{pg} / \mathrm{mL}$ with similar accuracy for event prediction. Measurement of BNP at exercise is straightforward and can easily be included in the context of standard exercise testing or exercise stress echocardiography. The biphasic behavior of myocardial strain may also account in part for conflicting reports on the value of preoperative speckle-tracking strain imaging in predicting postoperative LV dysfunction [14]. Although it requires further larger studies using mortality as an endpoint, our study suggests that patients with a high eBNP level might potentially benefit from early referral to surgery. It has also shown that elevated eBNP level may have an additive prognostic importance over resting BNP level.

\section{Study limitations}

Small sample size of the study and a cut-off value of $90 \mathrm{pg} /$ $\mathrm{mL}$ were data driven and need to be validated in larger studies. Also the use of overall mortality as an endpoint to test the prognostic implication of eBNP could probably be more robust.

\section{Conclusions}

In asymptomatic patients with primary MR, eBNP level pro- 
vides incremental prognostic value beyond what is achieved by demographic, echocardiographic data and resting BNP level. Those with elevated eBNP may be considered for early mitral valve surgery as they are at higher risk of reduced cardiac event-free survival, thus supporting the notion for the systematic measurement of BNP at the time of exercise testing or exercise stress echocardiography.

\section{Disclosures}

None.

\section{Conflicts of Interest}

None.

\section{References}

1. Enriquez-Sarano M, Akins CW, Vahanian A. Mitral regurgitation. Lancet. 2009;373(9672):1382-1394.

2. Nishimura RA, Schaff HV. Mitral regurgitation: timing of surgery. Valvular Heart Disease: companion to Braunwald's heart disease. Philadelphia: Saunders/Elsevier; 2009: p. 274-290.

3. Bando K, Kasegawa H, Okada Y, Kobayashi J, Kada A, Shimokawa T, Nasu M, et al. Impact of preoperative and postoperative atrial fibrillation on outcome after mitral valvuloplasty for nonischemic mitral regurgitation. J Thorac Cardiovasc Surg. 2005;129(5):1032-1040.

4. Gaasch WH, Meyer TE. Left ventricular response to mitral regurgitation: implications for management. Circulation. 2008;118(22):2298-2303.

5. Bonow RO, Carabello BA, Chatterjee $\mathrm{K}$, de Leon $\mathrm{AC}$, Jr., Faxon DP, Freed MD, Gaasch WH, et al. 2008 focused update incorporated into the ACC/AHA 2006 guidelines for the management of patients with valvular heart disease: a report of the American College of Cardiology/American Heart Association Task Force on Practice Guidelines (Writing Committee to revise the 1998 guidelines for the management of patients with valvular heart disease). Endorsed by the Society of Cardiovascular Anesthesiologists, Society for Cardiovascular Angiography and Interventions, and Society of Thoracic Surgeons. J Am Coll Cardiol. 2008;52(13):e1-142.

6. Enriquez-Sarano M, Miller FA, Jr., Hayes SN, Bailey KR, Tajik AJ, Seward JB. Effective mitral regurgitant orifice area: clinical use and pitfalls of the proximal isovelocity surface area method. J Am Coll Cardiol. 1995;25(3):703709.

7. Ziani AB, Latcu DG, Abadir S, Paranon S, Dulac Y, Guerrero F, Acar P. Assessment of proximal isovelocity surface area (PISA) shape using three-dimensional echocardiography in a paediatric population with mitral regurgitation or ventricular shunt. Arch Cardiovasc Dis. 2009;102(3):185-191.
8. Magne J, Lancellotti P, Pierard LA. Exercise pulmonary hypertension in asymptomatic degenerative mitral regurgitation. Circulation. 2010;122(1):33-41.

9. Haluska BA, Short L, Marwick TH. Relationship of ventricular longitudinal function to contractile reserve in patients with mitral regurgitation. Am Heart J. 2003;146(1):183-188.

10. Agricola E, Galderisi M, Oppizzi M, Schinkel AF, Maisano F, De Bonis M, Margonato A, et al. Pulsed tissue Doppler imaging detects early myocardial dysfunction in asymptomatic patients with severe mitral regurgitation. Heart. 2004;90(4):406-410.

11. Lancellotti P, Cosyns B, Zacharakis D, Attena E, Van Camp G, Gach O, Radermecker M, et al. Importance of left ventricular longitudinal function and functional reserve in patients with degenerative mitral regurgitation: assessment by two-dimensional speckle tracking. J Am Soc Echocardiogr. 2008;21(12):1331-1336.

12. Heimdal A, Stoylen A, Torp H, Skjaerpe T. Real-time strain rate imaging of the left ventricle by ultrasound. J Am Soc Echocardiogr. 1998;11(11):1013-1019.

13. Rosner A, Bijnens B, Hansen M, How OJ, Aarsaether E, Muller S, Sutherland GR, et al. Left ventricular size determines tissue Doppler-derived longitudinal strain and strain rate. Eur J Echocardiogr. 2009;10(2):271-277.

14. Song JM, Kang SH, Lee EJ, Shin MJ, Lee JW, Chung $\mathrm{CH}$, Kim DH, et al. Echocardiographic predictors of left ventricular function and clinical outcomes after successful mitral valve repair: conventional two-dimensional versus speckle-tracking parameters. Ann Thorac Surg. 2011;91(6):1816-1823.

15. de Isla LP, de Agustin A, Rodrigo JL, Almeria C, del Carmen Manzano M, Rodriguez E, Garcia A, et al. Chronic mitral regurgitation: a pilot study to assess preoperative left ventricular contractile function using speckletracking echocardiography. J Am Soc Echocardiogr. 2009;22(7):831-838.

16. Cea LB. Natriuretic peptide family: new aspects. Curr Med Chem Cardiovasc Hematol Agents. 2005;3(2):8798.

17. Detaint D, Messika-Zeitoun D, Avierinos JF, Scott C, Chen H, Burnett JC, Jr., Enriquez-Sarano M. B-type natriuretic peptide in organic mitral regurgitation: determinants and impact on outcome. Circulation. 2005;111(18):23912397.

18. Kerr AJ, Raffel OC, Whalley GA, Zeng I, Stewart RA. Elevated B-type natriuretic peptide despite normal left ventricular function on rest and exercise stress echocardiography in mitral regurgitation. Eur Heart J. 2008;29(3):363-370.

19. Klaar U, Gabriel H, Bergler-Klein J, Pernicka E, Heger M, Mascherbauer J, Rosenhek R, et al. Prognostic value of serial B-type natriuretic peptide measurement in asymptomatic organic mitral regurgitation. Eur J Heart Fail. 2011;13(2):163-169.

20. Magne J, Lancellotti P, Pierard LA. Exercise-induced changes in degenerative mitral regurgitation. J Am Coll Cardiol. 2010;56:300-309.

21. Magne J, Lancellotti P, Pierard LA. Exercise-induced 
changes in degenerative mitral regurgitation. J Am Coll Cardiol. 2010;56(4):300-309.

22. Huang WS, Lee MS, Perng HW, Yang SP, Kuo SW, Chang HD. Circulating brain natriuretic peptide values in healthy men before and after exercise. Metabolism. 2002;51(11):1423-1426.

23. Yousufuddin M, Henein MY, Flather M, Wang D, Shamim W, O'Sullivan C, Kemp M, et al. Incremental importance of peak-exercise plasma levels of endothelin-1 and natriuretic peptides in chronic heart failure. J Cardiovasc Pharmacol. 2001;38(3):468-473.

24. Kato M, Kinugawa T, Ogino K, Endo A, Osaki S, Igawa $\mathrm{O}$, Hisatome I, et al. Augmented response in plasma brain natriuretic peptide to dynamic exercise in patients with left ventricular dysfunction and congestive heart failure. J Intern Med. 2000;248(4):309-315.

25. Madaric J, Watripont P, Bartunek J, Casselman F, Vanderheyden M, Van Praet F, Wijns W, et al. Effect of mitral valve repair on exercise tolerance in asymptomatic patients with organic mitral regurgitation. Am Heart J. 2007;154(1):180-185.

26. Mak GS, DeMaria A, Clopton P, Maisel AS. Utility of B-natriuretic peptide in the evaluation of left ventricular diastolic function: comparison with tissue Doppler imaging recordings. Am Heart J. 2004;148(5):895-902.
27. Le Tourneau T, Messika-Zeitoun D, Russo A, Detaint D, Topilsky Y, Mahoney DW, Suri R, et al. Impact of left atrial volume on clinical outcome in organic mitral regurgitation. J Am Coll Cardiol. 2010;56(7):570-578.

28. Rusinaru D, Tribouilloy C, Grigioni F, Avierinos JF, Suri RM, Barbieri A, Szymanski C, et al. Left atrial size is a potent predictor of mortality in mitral regurgitation due to flail leaflets: results from a large international multicenter study. Circ Cardiovasc Imaging. 2011;4(5):473-481.

29. Montant P, Chenot F, Robert A, Vancraeynest D, Pasquet A, Gerber B, Noirhomme P, et al. Long-term survival in asymptomatic patients with severe degenerative mitral regurgitation: a propensity score-based comparison between an early surgical strategy and a conservative treatment approach. J Thorac Cardiovasc Surg. 2009;138(6):13391348.

30. Sutton TM, Stewart RA, Gerber IL, West TM, Richards AM, Yandle TG, Kerr AJ. Plasma natriuretic peptide levels increase with symptoms and severity of mitral regurgitation. J Am Coll Cardiol. 2003;41(12):2280-2287.

31. Pizarro R, Bazzino OO, Oberti PF, Falconi M, Achilli F, Arias A, Krauss JG, et al. Prospective validation of the prognostic usefulness of brain natriuretic peptide in asymptomatic patients with chronic severe mitral regurgitation. J Am Coll Cardiol. 2009;54(12):1099-1106. 